\title{
Prevalence and Determinants of Iron Deficiency Anemia in Adolescents Girls of Low Income Communities in Lahore
}

\author{
Fatima Hassan, ${ }^{1}$ Shafya Salim, ${ }^{2}$ Ayesha Humayun ${ }^{3}$
}

\section{Abstract}

Background: Iron deficiency anemia (IDA) in adolescent girls has strong health implications during reproductive years. Current research aimed to assess prevalence and determinants of iron deficiency anemia in adolescent girls of low income families residing in semi urban communities of Lahore, Pakistan.

Method: This cross sectional analytical study selected 116 unmarried adolescent girls between the ages of 13 - 19 years from low income families through convenience sampling from semi-urban communities. Dietary data was collected using 3 - day recall, whereas a self-constructed, structured questionnaire was used to collect data on socio-demographic factors. Hemoglobin and serum Ferritin levels were assessed along with an assessment of clinical signs and symptoms of folate and iron deficiency. Data was entered

\footnotetext{
${ }^{1}$ Assistant Professor at Higher Education Department, Punjab, Pakistan.

${ }^{2}$ Associate Professor at Government College of Home Economics, Gulberg, Lahore

${ }^{3}$ Professor and Head, Department of Public Health and Community Medicine, Deputy Director at Department of Undergraduate Medical Education, Shaikh Khalifa Bin Zayed AlNahyan Medical College and Shaikh Zayed Post Graduate Medical Institute, Shaikh Zayed Medical Complex, Lahore, Pakistan
}

Date of Submission: 08-02-2017

Date of Acceptance for Publication: 31-03-2017

Conflict of Interest: None

Funding Source: None

\section{Contribution}

All Authors have contributed in Study Design, Data Collection, Data Analysis, Data Interpretation, Manuscript Writing and Approval. and analyzed using SPSS version 21 .

Results: IDA was present in $68.8 \%$ of adolescent girls, of which $40.2 \%$ were moderately $(8-10 \mathrm{gm} / \mathrm{dl})$ and $28.8 \%$ were mildly $(10.9-11.9 \mathrm{gm} / \mathrm{dl})$ anemic. Working status $(\mathrm{p}<0.041)$, source of dietary iron $(\mathrm{p}<$ 0.001 ), frequency of heme iron consumption ( $\mathrm{p}<$ $0.001)$, protein consumption/day $(\mathrm{p}<0.001)$ and HEI score $(\mathrm{p}<0.001)$ showed statistically significant association with IDA. Binary regression analysis showed frequency of heme iron consumption $[\mathrm{AOR}=29.13$, 95\% CI (9.627 to 88.203)] and HEI score [AOR = $6.877,95 \% \mathrm{CI}(.065$ to 44.405$])$ to be the most significantly associated determinant of IDA. Mean $\mathrm{Hb}$ level was also significantly different between working and nonworking adolescents $(\mathrm{p}=0.001,95 \% \mathrm{CI}=-1.124$ to -0.322 ). Significant mean difference in serum Ferritin levels between working and nonworking adolescents $(\mathrm{p}=0.04$ [95\% CI $=-21.89$ to -0.50$]$ ) was also observed. $94 \%$ and $91 \%$ girls showed signs and symptoms of iron and folate deficiency respectively. However BMI, age, educational status of the girls and their parents were not found to be associated with IDA.

Conclusion: Prevalence of IDA was alarmingly high in adolescent girls of low socioeconomic class. Working status, source of dietary iron, frequency of heme iron consumption, protein consumption/day and HEI score were found to be determining anemia. Nutrition education targeting IDA is the need of the day to control and prevent this public health epidemic.

Key words: Adolescent girls, dietary intake, socio economic status, IDA.

\section{Introduction}

Anemia is the widely prevalent micronutrient deficiency which affects $24.8 \%$ of global population. The largest group affected by it is non pregnant women 
(30.2\%) of which most live in South East Asia ${ }^{1}$ Anemia in itself is not considered a fatal disease but it leads to low immunity and hence lower resistance to infections and frequent recurrence of diseases. Iron deficiency is also a major risk factor for maternal death and disability and of perinatal mortality. A severe iron deficiency may lead to cognitive impairment, decreased work productivity, and even death. ${ }^{2}$ Most of the interventions to overcome this nutritional deficiency are therefore focused on improving iron/nutritional status of pregnant women but many experts agree that in poverty-stricken populations, iron deficiency is not being adequately controlled by public health and nutrition interventions as they are currently implemented. ${ }^{3}$

Health systems' focus has shifted from maternal and child health to reproductive health based on life cycle approach. A major breakthrough in this regard especially in terms of overcoming nutritional deficiencies could be to begin nutritional interventions well before time they get married and enter motherhood. For this, adolescence can be the best time period to intervene. Studies have also shown adolescent years as the best time to intervene, to assist physical development and to prevent later maternal anemia. ${ }^{4,5}$ A good diet ensured during adolescent years lays a foundation for better health of future mothers and children.

Adolescence is a transitional period from childhood to adulthood during which certain problems may influence the health in later life. This is a vulnerable period in a girl's life as she experiences her first menarche and maturation of her sexual organs during this time period. ${ }^{4}$

However this age group remains to be the most neglected one and seldom proper nutrition is ensured during these critical growth years resulting in high incidence of nutritional deficiencies especially iron deficiency anemia. ${ }^{6}$

WHO has devised categories of public health significance according to prevalence of anemia. With prevalence at $4.9 \%$ or lower, it is categorized as normal, with prevalence at $5.0-19.9$ as mild and if prevalence is $20.0-39.9$ it is categorized as moderate. A prevalence above $40 \%$ is considered a severe public health problem according to this categorization. ${ }^{7}$ According to this classification of public health significance of anemia on the basis of prevalence estimated from blood levels of hemoglobin, Pakistan falls into severe category of public health significance.

The situation for female adolescents in Pakistan is equally worrisome as in other developing countries regarding IDA. A recent study has shown anemia to be the most prevalent micronutrient deficiency among adolescent girls. ${ }^{8}$ A similar study in the past has also reported IDA to be the most common type of anemia especially among females of Pakistan. ${ }^{9}$

The National Nutritional Survey Pakistan (NNS) in 2011 has also indicated that although there is no significant difference in nutritional status and intake of boys and girls but problems do arise for females in adolescence and adulthood. Inadequate dietary intake may lead to moderate and severe anemia, resulting largely from iron deficiency. The NNS highlighted that prevalence of IDA anemia as $49.3 \%$ in pregnant women and $60.3 \%$ in children in the province of Punjab, Pakistan. ${ }^{10}$

One of the major reasons of poor nutritional and health status in developing countries is poverty and lack of purchasing power due to limited income. Hence to make both ends meet, a lot of low income families send their women and children to work. Most of the young girls in such cases can only work as domestic helpers or housemaids because of poor or no education and also due to lack of skills which are required for other jobs. The present study assessed the prevalence and predictors of anemia in female adolescents belonging to low income families.

\section{Methods}

A cross sectional study was conducted between August 2013 to February 2014 at Shah di Khoee and Mochipura, both are urban slum communities in Lahore. These communities were selected through convenience sampling (geographical accessibility). Sample size was calculated on the basis of anemia prevalence among adolescent girls belonging to low income group in Pakistan which was found to be above $93 \%$ in early adolescents $(14-16)$ and $60 \%$ in late adolescents $(17-19)$, taking mean of these two groups, prevalence among adolescent girls was taken as $76.5 \%{ }^{8}$ Using single proportion estimation, confidence level at 0.95 and margin of error at $7 \%$, a sample size of 140 was calculated. Health status of the participants was evaluated through calculation of BMI, dietary analysis, blood hemoglobin and serum ferritin tests and presence or absence of clinical signs and symptoms of iron and folate deficiencies. The Healthy Eating Index (HEI) was used to analyze the dietary intake of the adolescent girls. HEI is a measure of diet quality and is a scoring metric that can be applied to 
any defined set of foods, such as formerly collected dietary data, to estimate a score. ${ }^{11 .}$

A 3 - day dietary recall was taken and it was ensured that weekend was included in the recall. It was used to calculate the caloric intake and frequency of recommended food groups. Assessment of nutritional status was done by calculating BMI from height and weight. Structured questionnaire was used to collect data on variables like demography, anthropometry, education, income level, employment status etc.

The research was conducted in compliance with the ethical principles for medical research involving human participants of the Helsinki Declaration. Verbal informed consent for interview and obtaining blood sample was taken from all participants and their parents as well, in front of a witness. The right to privacy, anonymity, voluntary participation and confidentiality were observed.

Descriptive statistics were used along with fisher exact test and Independent sample t-test for comparison of means in two groups. Statistical analysis was carried out using Statistical Package for the Social Sciences (SPSS v.17).

Out of 140 participants, analysis was done on 112 forms due to incomplete information in 18 forms and damage to 10 forms. Student t-test with $95 \%$ Confidence interval (CI) was used to check differences in means of BMI, $\mathrm{Hb}$ and Ferritin levels of working and non-working adolescents. Exact test was used to examine association of anemia with socio-demographic and dietary predictors. $P \leq 0.05$ was considered statistically significant. Logistic binary regression was then applied to identify the independent predictors of IDA in the adolescent girls. The dietary intake was analyzed through modified HEI (Healthy Eating Index, 2010) scoring. The score was derived out of 100, allocating 20 points to grains, vegetables, fruits, dairy and meat/legumes group each. The scores were rated as good $(>80)$, moderate $(79-50)$ and poor $(<50)$. As none of the participant managed to score in good and moderate category, quartiles were made and first two categories/quartiles denoted very poor and poor scores. The third and fourth categories represented moderately and mildly poor scores.

\section{Results}

Analysis of the data showed that anemia was widely prevalent in adolescent girls and $68.8 \%$ adolescent girls were found to be anemic $(<11.9 \mathrm{gm} / \mathrm{dl})$, with
$40.2 \%$ falling in moderate $(8-10 \mathrm{gm} / \mathrm{dl})$ and $28.8 \%$ in the mild $(10.9-11.9 \mathrm{gm} / \mathrm{dl})$ anemia category. None of the participants was found to be severely anemic $(<8 \mathrm{gm} / \mathrm{dl})$ in both groups. Working status was also found to be significantly associated with anemia as 44 $(57.1 \%)$ working adolescents were found to be anemic as compared to $33(37.1 \%)$ of nonworking adolescents. However there was no significant difference between anemia prevalence in late $(16-19)$ and early $(13-15)$ adolescents. The study also found that all the participants in both had normal serum ferritin levels despite their poor dietary iron intake and low $\mathrm{Hb}$ levels. It was also observed that all the adolescents regardless of working status were taking calories below recommended intake, with a mean caloric intake of $1070 \mathrm{cal} / \mathrm{day}$. In the present study $58 \%$ of the participants were found to be under weight with BMI $<18.5 \mathrm{~m} 2$, whereas $33.9 \%$ were falling in the normal category with BMI $18.5-24.9 \mathrm{~m} 2$. Only a small percentage of $7.9 \%$ and $0.9 \%$ fell in overweight and obese category with BMI $25-29.9$ and $>30$ respectively. Around $45 \%$ of participants' fathers were not literate and the percentage was even higher for the mothers of the participants $(65 \%)$. About $26 \%$ of the adolescent girls were also not literate themselves (Table 1).

Around $80 \%$ of the participants were consuming iron from non-heme sources, with less than $20 \%$ taking iron from both sources (heme and non heme). These girls were also not consuming any fruit or vegetable which could have provided vitamin $\mathrm{C}$, needed for absorption of iron. Association of anemia with heme iron consumption was found to be significant with $\mathrm{p}$ value 0.000 . Similarly the association between source of iron in the diet and anemia was significant at pvalue 0.000 as $61 \%$ of the anemic adolescent girls were consuming iron from non-heme source. A significant association between frequency of consumption of iron from heme source and anemia was observed, with $p<0.05$ as only $7.8 \%$ of anemic consumed from heme source twice a week as compared to $65.7 \%$ of non-anemic participants (Table 2).

Similarly a significant association was found between source of iron in diet and anemia with $p<0.05$ as $82.9 \%$ of non-anemic participants were consuming iron from both heme and non-heme sources as compared to only $31.2 \%$ of anemic participants. About $68.8 \%$ of the anemic participants were consuming single source of iron that was non-heme source as compare to a mere $17 \%$ of non-anemic (Table 2).

A highly significant association with $\mathrm{p}<0.05$ was found between number of protein servings consumed 
and anemia as it was found that only $3.9 \%$ of the anemic adolescents were taking recommended servings of protein as compared to $31.4 \%$ of non anemic (Table 2).

Significant association between anemia and HEI score was also observed $\mathrm{p}<0.05(0.001)$. Around $75 \%$ of the anemic adolescent girls fell into first two quartiles of HEI score which denoted very poor and poor score as compare to $48 \%$ of the non anemic girls (Table 2).

An independent-samples t-test was conducted to compare blood $\mathrm{Hb}$ level and there was a significance difference between means of hemoglobin level and serum ferritin levels of both groups. A significant difference of means between hemoglobin level of working $(\mathrm{M}=10.82$, S.D $= \pm 1.07)$ and nonworking adolescents $(M=11.55$, S.D $= \pm 1.06)$ was observed. Similar significant difference of means in serum ferritin levels between working $(M=45.03$, S.D $=8.47)$ and nonworking adolescents $(M=56.23, S . D=39.49)$ was also observed (Table 3).

More than $94 \%$ and $91 \%$ girls showed the signs and symptoms of iron and folate deficiency respectively (Table 4). There was a significant association between signs and symptoms of folate deficiency and anemia with $p<0.05$ as $54.5 \%$ and $23.4 \%$ of anemic adolescents showed moderate and severe signs and symptoms of folate deficiency respectively. Whereas only $8.6 \%$ of non anemic showed signs of moderate deficiency and none showed severe deficiency symptoms. However $60 \%$ of non anemic were found to be showing signs of mild deficiency signs and symptoms. Similarly a significant association between signs and symptoms of iron deficiency and anemia with $\mathrm{p}<0.05$ as $44.2 \%$ and $49.4 \%$ of anemic adolescents showed moderate and severe signs and symptoms of iron deficiency respectively as compare to only $8.6 \%$ of non anemic who showed signs of moderate deficiency and again none showed severe deficiency signs and symptoms. However like folate deficiency signs $82.9 \%$ of non anemic were found to be showing signs of mild deficiency (Table 4).

Binary logistic regression analysis was done to check association of different variables with IDA among adolescent girls. Simple Odds Ratio was also calculated separately for each variable (Table 5). Final regression model showed frequency of iron intake from heme source to be the most significantly associated predictor of Iron Deficiency Anemia (AOR = 29.139, 95\% CI, 9.627 to 88.203) among adolescent girls followed by Healthy Eating Index scores (AOR = $6.877,95 \%$ CI, 1.065 to 44.405 ) (Table 6).

Table 1: Association of Anemia with Socio-demographic Predictors in Adolescent Girls.

\begin{tabular}{|c|c|c|}
\hline Variables & Frequency $(\%)$ & P-value \\
\hline \multicolumn{2}{|l|}{ Age } & \multirow{3}{*}{0.30} \\
\hline Early adolescents $(13-15)$ & $51(45.5 \%)$ & \\
\hline Late adolescents $(16-19)$ & $61(54.5 \%)$ & \\
\hline \multicolumn{2}{|l|}{ BMI } & \multirow{4}{*}{0.26} \\
\hline Normal & $38(33.9 \%)$ & \\
\hline Below & $65(58.1 \%)$ & \\
\hline Above normal & $09(08 \%)$ & \\
\hline \multicolumn{2}{|l|}{ Working Status } & \multirow{3}{*}{$0.04 *$} \\
\hline Employed and anemic & $44(57.1 \%)$ & \\
\hline Not employed and anemic & $33(42.9 \%)$ & \\
\hline \multicolumn{2}{|l|}{ Participants Education } & \multirow{4}{*}{0.17} \\
\hline Grade V & $31(27.7 \%)$ & \\
\hline Grade VIII & $25(22.3 \%)$ & \\
\hline Grade X & $20(17.9 \%)$ & \\
\hline
\end{tabular}




\begin{tabular}{|c|c|c|}
\hline Grade XII & $06(5.4 \%)$ & \\
\hline Bachelors and above & $01(0.9 \%)$ & \\
\hline Illiterate & $29(25.9 \%)$ & \\
\hline \multicolumn{2}{|l|}{ Fathers Education } & \multirow{7}{*}{0.74} \\
\hline Grade V & $27(24.1 \%)$ & \\
\hline Grade VIII & $14(12.5 \%)$ & \\
\hline Grade X & $19(17 \%)$ & \\
\hline Grade XII & $01(0.9 \%)$ & \\
\hline Bachelors and above & $1(0.9 \%)$ & \\
\hline Illiterate & $50(44.6 \%)$ & \\
\hline \multicolumn{2}{|l|}{ Mothers Education } & \multirow{7}{*}{0.30} \\
\hline Grade V & $24(21.4 \%)$ & \\
\hline Grade VIII & $08(7.1 \%)$ & \\
\hline Grade X & $04(3.6 \%)$ & \\
\hline Grade XII & - & \\
\hline Bachelors and above & $03(2.7 \%)$ & \\
\hline Illiterate & $73(65.2 \%)$ & \\
\hline \multicolumn{2}{|c|}{ Current Educational Status } & \multirow{3}{*}{0.063} \\
\hline Student & $48(42.9 \%)$ & \\
\hline Not student & $64(57.1 \%)$ & \\
\hline
\end{tabular}

Fischer Exact test was applied

*statistically significant

Table 2: Association of Anemia with Dietary Factors.

\begin{tabular}{|c|c|c|c|}
\hline \multirow{2}{*}{ Variables } & \multicolumn{2}{|c|}{ Anemia $(\mathrm{N}=112) \mathbf{n}(\%)$} & \multirow{2}{*}{ p-value } \\
\hline & Yes & No & \\
\hline \multicolumn{4}{|l|}{ Source of Dietary Iron } \\
\hline Heme iron & $2(2.6 \%)$ & $3(8.6 \%)$ & \multirow{4}{*}{$<0.001$} \\
\hline Non heme & $47(61.0 \%)$ & $2(5.7 \%)$ & \\
\hline Both heme and non-heme & $24(31.2 \%)$ & $29(82.9 \%)$ & \\
\hline No direct consumption of iron & $4(5.2 \%)$ & $1(2.9 \%)$ & \\
\hline \multicolumn{3}{|c|}{ Frequency of Iron Intake from Heme Source } & \\
\hline Daily & $2(2.6 \%)$ & $3(8.6 \%)$ & \multirow{4}{*}{$<0.001$} \\
\hline Biweekly & $6(7.8 \%)$ & $23(65.7 \%)$ & \\
\hline Weekly & $43(55.8 \%)$ & $9(25.7 \%)$ & \\
\hline Monthly & $26(33.8 \%)$ & $0(.0 \%)$ & \\
\hline
\end{tabular}




\begin{tabular}{|c|c|c|c|}
\hline Protein Servings/Day & & & \\
\hline 2 servings & $3(3.9 \%)$ & $11(31.4 \%)$ & \multirow{5}{*}{$<0.001^{*}$} \\
\hline 1.5 servings & $7(9.1 \%)$ & $5(14.3 \%)$ & \\
\hline 1 servings & $35(45.5 \%)$ & $14(40.0 \%)$ & \\
\hline 0.5 servings & $22(28.6 \%)$ & $4(11.4 \%)$ & \\
\hline 0 serving & $10(13.0 \%)$ & $1(2.9 \%)$ & \\
\hline \multicolumn{4}{|l|}{ HEI Score } \\
\hline 1st Category & $27(35.1 \%)$ & $9(25.7 \%)$ & \multirow{4}{*}{$<0.001 *$} \\
\hline 2nd Category & $31(40.3 \%)$ & $8(22.9 \%)$ & \\
\hline 3rd Category & $16(20.8 \%)$ & $8(22.9 \%)$ & \\
\hline 4th Category & $3(3.9 \%)$ & $10(28.6 \%)$ & \\
\hline
\end{tabular}

*statistically significant

Table 3: Comparison of Means of Biochemical Parameters of Working and Nonworking Adolescent Girls.

\begin{tabular}{|c|c|c|c|c|c|c|c|}
\hline Variable & Working Status & Mean & SD & $d f$ & $95 \% \mathrm{CI}$ & t-value & p-value \\
\hline \multirow{2}{*}{ Hemoglobin } & YES & 10.82 & \pm 1.07 & 110 & \multirow{2}{*}{-1.124 to -0.322} & \multirow{2}{*}{-3.572} & \multirow{2}{*}{$0.001 *$} \\
\hline & NO & 11.55 & \pm 1.06 & 110 & & & \\
\hline \multirow{2}{*}{$\begin{array}{l}\text { Serum } \\
\text { Ferritin level }\end{array}$} & YES & 45.03 & \pm 8.47 & 110 & \multirow{2}{*}{-21.89 to -0.507} & \multirow{2}{*}{-2.076} & \multirow{2}{*}{$0.04 *$} \\
\hline & NO & 56.23 & \pm 39.49 & 110 & & & \\
\hline
\end{tabular}

*statistically significant

Table 4: Association of Anemia with signs and symptoms of Iron and Ferritin deficiency.

\begin{tabular}{|c|c|c|c|c|c|c|c|}
\hline \multirow{2}{*}{\multicolumn{2}{|c|}{ Signs \& Symptoms }} & \multicolumn{3}{|c|}{ Anemia } & \multirow{3}{*}{$\begin{array}{c}\text { Absent } \\
0(.0 \%)\end{array}$} & \multirow{2}{*}{$\begin{array}{c}\text { Fisher Exact } \\
\text { value }\end{array}$} & \multirow{2}{*}{ p-value } \\
\hline & & Mild & Moderate & Severe & & & \\
\hline \multirow{2}{*}{ Iron deficiency } & YES & $5(6.5 \%)$ & $34(44.2 \%)$ & $38(49.4 \%)$ & & \multirow{2}{*}{79.7} & \multirow{2}{*}{$<0.001^{*}$} \\
\hline & NO & $29(82.9 \%)$ & $3(8.6 \%)$ & $0(.0 \%)$ & $3(8.6 \%)$ & & \\
\hline \multirow{2}{*}{ Folate deficiency } & YES & $17(22.1 \%)$ & $42(54.5 \%)$ & $18(23.4 \%)$ & $0(.0 \%)$ & \multirow{2}{*}{57.89} & \multirow{2}{*}{$<0.001^{*}$} \\
\hline & NO & $21(60.0 \%)$ & $3(8.6 \%)$ & $0(.0 \%)$ & $11(31.4 \%)$ & & \\
\hline
\end{tabular}

*statistically significant

Table 5: Binary Logistic Regression Analysis for the Association of Different Variables with Iron Deficiency Anemia among Adolescent Girls.

\begin{tabular}{|c|c|c|c|c|c|c|c|}
\hline \multirow{2}{*}{ Variable } & \multirow{2}{*}{$\begin{array}{c}\text { Simple Odds } \\
\text { Ratio }\end{array}$} & \multicolumn{2}{|c|}{ 95\% CI for $\operatorname{EXP(B)}$} & \multirow{2}{*}{$\begin{array}{c}\text { Adjusted } \\
\text { Odds Ratio }\end{array}$} & \multicolumn{2}{|c|}{$95 \%$ CI for $\operatorname{EXP}(B)$} & \multirow[b]{2}{*}{ Sig. } \\
\hline & & Lower & Upper & & Lower & Upper & \\
\hline HEI score & 3.183 & .672 & 15.064 & 5.236 & .714 & 38.368 & .078 \\
\hline
\end{tabular}




\begin{tabular}{|l|c|c|c|c|c|c|c|}
\hline Caloric Intake & 2.273 & .307 & 16.831 & .306 & .014 & 6.894 & .452 \\
\hline Protein intake & 17.188 & 3.557 & 83.044 & 3.975 & .641 & 24.650 & .138 \\
\hline Meal skipping & 1.778 & .644 & 4.905 & 1.118 & .224 & 5.591 & .892 \\
\hline $\begin{array}{l}\text { Iron intake from heme } \\
\text { Source }\end{array}$ & 24.917 & 8.686 & 71.472 & 37.277 & 9.589 & 144.902 & $.000^{*}$ \\
\hline Employment status & 2.424 & 1.057 & 5.561 & .592 & .088 & 3.961 & .589 \\
\hline Participants' education & 2.717 & .939 & 7.862 & .737 & .108 & 5.042 & .756 \\
\hline $\begin{array}{l}\text { Participants' father } \\
\text { education }\end{array}$ & 1.565 & .690 & 3.549 & .778 & .199 & 3.048 & .719 \\
\hline $\begin{array}{l}\text { Participants' Mother } \\
\text { education }\end{array}$ & 1.656 & .726 & 3.780 & 1.514 & .387 & 5.929 & .551 \\
\hline Student or not & 3.333 & 1.409 & 7.886 & 1.989 & .255 & 15.518 & .512 \\
\hline Birth health status & 2.906 & .915 & 9.232 & 2.988 & .540 & 16.532 & .210 \\
\hline $\begin{array}{l}\text { Previous 6 months } \\
\text { health status }\end{array}$ & 1.250 & .558 & 2.798 & 1.302 & .356 & 4.762 & .690 \\
\hline Frequency of illness & 1.472 & .642 & 3.378 & .788 & .175 & 3.545 & .756 \\
\hline Present health status & 2.239 & .782 & 6.407 & 1.288 & .191 & 8.673 & .795 \\
\hline Periods regularity & .329 & .083 & 1.309 & .245 & .030 & 1.987 & .188 \\
\hline
\end{tabular}

Table 5(b): Final Model of Bivariate Regression showing Association of Most Significant Variables with Iron Deficiency Anemia among Adolescent Girls.

\begin{tabular}{|c|c|c|c|c|c|c|c|}
\hline \multirow{2}{*}{ Variable } & \multirow{2}{*}{$\begin{array}{l}\text { Simple Odds } \\
\text { Ratio }\end{array}$} & \multicolumn{2}{|c|}{$95 \%$ C.I. for $\operatorname{EXP}(B)$} & \multirow{2}{*}{$\begin{array}{c}\text { Adjusted } \\
\text { Odds Ratio }\end{array}$} & \multicolumn{2}{|c|}{ 95\% C.I. for $\operatorname{EXP}(B)$} & \multirow[b]{2}{*}{ p-value } \\
\hline & & Lower & Upper & & Lower & Upper & \\
\hline HEI score & 3.183 & .952 & 4.105 & 6.877 & 1.065 & 44.405 & $.043 *$ \\
\hline $\begin{array}{l}\text { Iron intake from heme } \\
\text { source }\end{array}$ & 2.273 & .565 & 35.609 & 29.139 & 9.627 & 88.203 & $<0.001 *$ \\
\hline
\end{tabular}

*statistically significant

\section{Discussion}

Normal Hemoglobin levels for girls are $12-14 \mathrm{~g} / \mathrm{dl}$. WHO has established cut off levels for mild, moderate and severe anemia as $11-11.9 \mathrm{~g} / \mathrm{dl}$ classified as mild, $8-10.9 \mathrm{~g} / \mathrm{dl}$ as moderate and below $8 \mathrm{~g} / \mathrm{dl}$ as severe anemia. $^{7}$

Serum ferritin concentrations indicate blood iron stores. Normal serum ferritin levels for females are 12$150 \mathrm{ng} / \mathrm{dl} .^{12}$ The present study found that all the parti- cipants had normal serum ferritin levels despite their poor dietary iron intake which points towards a mechanism which needs to be investigated as all the participants had iron stores despite the mineral's inadequate intake.

In the current study, high prevalence of anemia was observed as $68.8 \%$ girls found to be anemic ( $<11.9 \mathrm{gm} / \mathrm{dltr})$, out of which $40.2 \%$ fell in moderate $(8-10 \mathrm{gm} / \mathrm{dltr})$ and $28.8 \%$ in the mild $(10.9-11.9$ 
gm/dltr) anemia category. None of the subject was found to be severely anemic $(<8 \mathrm{gm} / \mathrm{dltr})$. Previous studies carried out in Pakistan had also observed the similar findings. ${ }^{8}$ Previous studies have also reported iron absorption from diets consumed in developing countries to be adequate. This shows that the food consumed by most of the people in Pakistan has adequate iron content, the absorption is also adequate but the problem may lie in the feeding habits. ${ }^{13}$

Although it is a known fact that iron from heme sources are better absorbed as compared to iron from non-heme sources, it also must not be forgotten that heme source is generally expensive hence restricting its use by families with low incomes. With low purchasing power it remains difficult for families belonging to low income group to afford high prices of meat and meat products hence high prevalence of anemia can be due to iron intake from nonheme sources as around $80 \%$ of the participants were consuming iron from non heme sources, with less than $20 \%$ taking iron from both heme and non heme sources. A previous study on anemia in Tanzania has also established that in developing countries dietary iron intake appears to be high, but most of it is of non heme origin. ${ }^{16}$ Studies on bio availability of iron have established that when body iron stores are low, the absorption of non-heme iron increases, but this also usually does not exceed $20 \% .^{15-18}$

The present study also showed lesser consumption of iron from heme sources and a significant association was found between source of iron in diet and anemia with $p<0.05$ as only $31.2 \%$ of anemic participants were consuming iron from both heme and nonheme sources as compared to $82.9 \%$ of non-anemic participants. About $68.8 \%$ of the anemic participants were consuming single source of iron that too was non-heme source while $17 \%$ of non-anemic consumed iron from non-heme source only. This confirmed finding of previous study on young women in Bangalore, India which also reported low intake of heme iron among anemic girls. ${ }^{14}$

There was found to be a significant association between frequency of iron consumption from heme source and anemia as consumption per week from heme source was significantly low in anemic participants $(7.8 \%)$ as compared to non-anemic participants, of which $65.7 \%$ were consuming iron from heme source twice a week. Iron requirements are increased in adolescence because of the greater muscle mass and blood volume associated with the growth spurt. In addition, the onset of menstruation increases the iron requirements for females. Adolescents need to consume foods with a high availability of iron, such as red meats, or eat combinations of good non-heme sources of iron along with foods rich in vitamin C. ${ }^{15}$

Past studies have shown that with decrease in budget, fruits are the first food to be omitted from menu. ${ }^{16}$ These girls were also not consuming any fruit or vegetable which could have provided vitamin $\mathrm{C}$, needed for absorption of iron.

Studies have also shown that anemic girls also have less caloric intake. ${ }^{17,18}$ Same trend has been observed in Pakistan where it has been reported that half of the Pakistani population has less caloric intake than standard requirement, further $50 \%$ women were found to have caloric intake below RDA. ${ }^{19}$

Whereas obesity is considered to be one of the most worrisome nutritional problem of the Western and most importantly developed countries, under nutrition still remains to be one of the top health problem of the developing world. Food insecurity and low purchasing power remains an area demanding attention of the developed world where food access is causing epidemic of obesity. Similar situation was observed in this study where all the participants were taking well below recommended caloric intake as the mean caloric intake was a mere $1070 \mathrm{cal} /$ day whereas the recommended dietary allowance of energy for young Pakistani females has been fixed at $2150 \mathrm{Kcal}$ per day. ${ }^{20}$ This can be a strong reason for low BMI of the adolescents as $58 \%$ of the participants were found to be under weight with BMI $<18.5 \mathrm{~m} 2$, whereas $33.9 \%$ were falling in the normal category with BMI $18.5-$ $24.9 \mathrm{~m} 2$. Only a small percentage of $7.9 \%$ and $0.9 \%$ fell in overweight and obese category with BMI 25 29.9 and $>30$ respectively. Similar findings were observed in the previous studies that malnourished girls had low BMI. ${ }^{21}$ However no significant association was found between anemia and below normal BMI. This finding is not in line with the previous findings which observed below normal BMI in anemic adolescent girls. $^{8,21}$

Low family incomes often drive young girls from low income families to work outside their homes. Most often these young girls leave school early to contribute in family income. Most of these adolescents skip meals and have poor health status. Working Status was also significantly associated with anemia as $57.1 \%$ of the employed participants were anemic as compared to $42.9 \%$ of not employed. Significant differences in means in $\mathrm{Hb}$ and ferritin levels of working and nonworking adolescent girls were found. Past 
studies have shown anemia to be significantly associated with late and early adolescents. ${ }^{8,22,23}$ However in the present study, no significant association between age and anemia was found.

Signs and Symptoms of Folate deficiency were widely prevalent and showed a significant association with anemia. A vast majority of $54.5 \%$ and $23.4 \%$ of anemic adolescents showed moderate and severe signs and symptoms of folate deficiency respectively. However $60 \%$ of nonanemic adolescents were also found to be showing signs of mild deficiency signs and symptoms which might be an indication that their borderline normal hemoglobin level can drop below normal with the slightest infection or fluctuation in the diet.

Similarly a significant association of anemia with signs and symptoms of iron deficiency was also observed as $44.2 \%$ and $49.4 \%$ of anemic adolescents showed moderate and severe signs and symptoms of iron deficiency respectively as compared to only $8.6 \%$ of non anemic who showed signs of moderate deficiency and again none showed severe deficiency signs and symptoms. However $82.9 \%$ of non-anemic were also found to be showing signs of mild deficiency. This finding shows that even most of the adolescents, who were nonanemic had their Hemoglobin level at borderline of being normal (12 gm/dltr).

All the participants did poor on (HEI) scores and again a significant association was shown between anemia and HEI score. Around $75 \%$ of the anemic adolescent girls fell into first two quartiles of HEI score which denoted very poor and poor score as compared to $48 \%$ of the non anemic girls who fell in third and fourth categories.

Consumption of recommended intake of protein servings in a day was found to be a major possible cause of anemia in adolescent girls. It was found that a vast majority of the adolescents who were found to be anemic were not consuming recommended protein servings of this age group as only $3.9 \%$ of the anemic adolescents were taking recommended servings of protein whereas $31.4 \%$ of non anemic managed to take recommended number of servings of this age group. A highly significant association was found between number of protein servings consumed and anemia. This also showed the findings of this study to be in consistence with the previous studies carried out in Pakistan and India that showed adolescent girls were consuming less than recommended sources of protein and that was mainly of plant origin. ${ }^{21}$

No association was observed with anemia and education of parents, similar findings were reported in another study on adolescents carried out in India, in the same social and cultural setting. ${ }^{23}$

The present study tries to assess and compare iron deficiency status of working and non-working adolescent girls in Pakistan and to identify the determining factors of anemia. Although a few studies have been conducted in the past on adolescent girls but none of the study was community based according to the knowledge of this author. The study is especially important from the perspective that working adolescent girls were also participants of this study. However, as the study was carried out on small scale due to financial, cultural and time constraints on the part of researcher, the results cannot be generalized to all the working adolescents. Nevertheless, this descriptive analytical study provides a new dimension for future studies in the same socio economic and geographical settings on a larger scale.

\section{Conclusion}

It can be concluded from this study that anemia is widely prevalent among adolescent girls from low socio economic status and the prevalence is higher among the working adolescents. Working status and dietary factors such as protein intake, source of iron in the diet and overall quality of the diet are significant determinants of iron deficiency anemia. The study has also shown a significant association between protein intake and anemia hence pointing towards a possibility of protein deficiency to be a major cause of anemia as nearly all the participants showed ferritin levels within normal range which shows adequate iron storage. Similarly lack of iron intake from heme sources was identified by binary logistic regression as the most significantly associated determinant of IDA followed by Healthy Eating score. 


\section{References}

1. De Benoist B, McLean E, Egli I, Cogswell M. WHO global database on anaemia. Geneva: WHO, 2008: 1993-2005.

2. Stoltzfus RJ. Iron deficiency: global prevalence and consequences. Food and nutrition bulletin, 2003; 24 (4): 99-103.

3. Maberly GF, Haxton DP, van der Haar F. Iodine deficiency: consequences and progress toward elimination. Food and nutrition bulletin, 2003; 24 (4): 91-S8.

4. Delisle Hln. Nutrition in adolescence-issues and challenges for the health sector. Issues in adolescent health and development, 2005.

5. Srinivas V, Mankeshwar R. Prevalence and determinants of nutritional anemia in an urban area among unmarried adolescent girls: A community-based crosssectional study. International Journal of Medicine and Public Health, 2015; 5 (4): 283.

6. Organization WH. Adolescent nutrition: a review of the situation in selected South-East Asian countries, 2006.

7. Organization WH. WHO; 2011. Haemoglobin concentrations for the diagnosis of anaemia and assessment of severity. WHO/NMH/NHD/MNM/11.1.

8. Talpur A, Khand AA, Laghari ZA. Prevalence of Anemia in Adolescent Girls. Pak J Physiol. 2012; 8: 1.

9. Idris M. Iron deficiency anaemia in moderate to severely anaemic patients. Journal of Ayub Medical College Abbottabad, 2015; 17 (3): 3.

10. Levinson FJ. Engaging Development Partners in Efforts to Reverse Malnutrition Trends in Pakistan. IDS Bulle-
16. Pena-Rosas JP, De-Regil LM, Rogers LM, Bopardikar A, Panisset U. Translating research into action: WHO evidence-informed guidelines for safe and effective micronutrient interventions. The Journal of nutrition, 2012; 142 (1): 197-204.

17. Foo LH, Khor GL, Tee E-s, Dhanaraj P. Determinants of iron status in Malaysian adolescents from a rural community. International journal of food sciences and nutrition, 2004; 55 (6): 517-25.

18. Kabir Y, Shahjalal HM, Saleh F, Obaid W. Dietary pattern, nutritional status, anaemia and anaemia-related knowledge in urban adolescent college girls of Bangladesh. JPMA The Journal of the Pakistan Medical Association, 2010; 60 (8): 633.

19. Lloyd CB, Mahmood A. The Changing Transitions to Adulthood in a Comparative Perspective: the Case of Pakistan [with Comments]. The Pakistan Development Review, 2004: 441-67.

20. Khan M, Khan M, Commission P. Food composition table for Pakistan. Peshawar: University of Agriculture, 2001.

21. Hanan S, Gilani A, Haq I. Anemia in adolescent college girls: effect of age, nutritional status and nutrient intake. Pakistan Journal of Science, 2010; 62 (4): 207-10.

22. Biradar SS, Biradar SP, Alatagi A, Wantamutte A, Malur P. Prevalence of anaemia among adolescent girls: a one year cross-sectional study. J Clin Diagn Res. 2012; 6: 372-7.

23. Chauhan A, Chauhan S, Bala D. Anemia among Adolescent Girls and its socio-demographic Associates. 